\title{
A Scoping Review of Digital Tools to Reduce Sedentary Behavior or Increase Physical Activity in Knowledge Workers
}

\author{
Ida Damen ${ }^{1, *(\mathbb{D})}$, Hans Brombacher ${ }^{1}$, Carine Lallemand ${ }^{1,2} \mathbb{D}$, Rens Brankaert ${ }^{1,3}$, \\ Aarnout Brombacher ${ }^{1}$, Pieter van Wesemael ${ }^{4}$ and Steven Vos $1,5, *$ (D) \\ 1 Department of Industrial Design, Eindhoven University of Technology, 5600 MB Eindhoven, \\ The Netherlands; j.g.brombacher@student.tue.nl (H.B.); c.e.lallemand@tue.nl (C.L.); \\ r.g.a.brankaert@tue.nl (R.B.); a.c.brombacher@tue.nl (A.B.) \\ 2 HCI Research Group, University of Luxembourg, 4365 Esch-sur-Alzette, Luxembourg \\ 3 School for Allied Health Professions, Fontys University of Applied Sciences, 5600 AH Eindhoven, \\ The Netherlands \\ 4 Department of the Built Environment, Eindhoven University of Technology, 5600 MB Eindhoven, \\ The Netherlands; p.j.v.v.wesemael@tue.nl \\ 5 School of Sport Studies, Fontys University of Applied Sciences, 5644 HZ Eindhoven, The Netherlands \\ * Correspondence: a.a.j.m.damen@tue.nl (I.D.); s.vos@tue.nl (S.V.)
}

Received: 1 October 2019; Accepted: 7 January 2020; Published: 13 January 2020

\begin{abstract}
Background: There is increasing interest in the role that technology can play in improving the vitality of knowledge workers. A promising and widely adopted strategy to attain this goal is to reduce sedentary behavior (SB) and increase physical activity (PA). In this paper, we review the state-of-the-art SB and PA interventions using technology in the office environment. By scoping the existing landscape, we identified current gaps and underexplored possibilities. We discuss opportunities for future development and research on SB and PA interventions using technology. Methods: A systematic search was conducted in the Association for Computing Machinery digital library, the interdisciplinary library Scopus, and the Institute of Electrical and Electronics Engineers Xplore Digital Library to locate peer-reviewed scientific articles detailing SB and PA technology interventions in office environments between 2009 and 2019. Results: The initial search identified 1130 articles, of which 45 studies were included in the analysis. Our scoping review focused on the technologies supporting the interventions, which were coded using a grounded approach. Conclusion: Our findings showed that current SB and PA interventions using technology provide limited possibilities for physically active ways of working as opposed to the common strategy of prompting breaks. Interventions are also often offered as additional systems or services, rather than integrated into existing office infrastructures. With this work, we have mapped different types of interventions and provide an increased understanding of the opportunities for future multidisciplinary development and research of technologies to address sedentary behavior and physical activity in the office context.
\end{abstract}

Keywords: technological interventions; workplace; knowledge workers; scoping review; physical activity; sedentary behavior

\section{Introduction}

A crucial factor that negatively affects a person's vitality is the lack of physical activity (PA) and high levels of sedentary behavior (SB) throughout the day [1]. Prolonged periods of sedentary behavior, characterized by waking behavior equal to or below 1.5 METs [2], can have a severe negative 
effect on health [3-5]. Sedentary behavior is associated with the development of diseases such as type II diabetes, cardiovascular diseases, colon and breast cancer, increased morbidity, and premature mortality [3,5-10]. Our increasingly sedentary lives have thus become a major public health risk [11]. Conversely, engaging in physical activity, defined as any body movement that raises energy expenditure above resting metabolic rate [12], is positively linked to improved vitality [1].

To combat the negative health effects of prolonged sitting, it is important to integrate physical activity into daily routines and reduce the amount of sedentary behavior. This, however, proves difficult in office contexts. We currently spend up to $71 \%$ of our working hours sitting [13], and trend analysis indicates that sedentary behavior will continue to increase in the near future [14]. To counteract this trend, there is a growing need to investigate how to increase PA and reduce SB in office settings. In addition, a growing body of work shows that increasing and embedding physical activities in work routines does not only increase workers' health and wellbeing, but also improves social interaction and work performance [15].

A myriad of interventions targeting sedentary behavior or physical activity in workplace contexts have been developed by researchers from different disciplines. In recent years, several systematic reviews have assessed these interventions [16-19]. The reviews have shown that only a small portion of the interventions that were assessed had a digital component. This is despite the fact that digital technologies have the potential to "revolutionize the way individuals can monitor and improve their health" [20]. For instance, one might use a personalized services such as Google Goals, a calendar application to integrate personal goals into a user's digital calendar [21]. These types of tools may increase reflection on personal goals and thereby advance the effectiveness of the intervention [22].

Few reviews could be found that focused on or included interventions using technology. In a systematic review on the effectiveness of SB workplace interventions by Chau et al. [23], three studies had a technological element [23-26] consisting of either email or the use of a pedometer. Another four studies were included in a review by Shrestha et al. [27], involving computer prompts [28-30] and e-newsletters [31]. In a study by Bort-Roig et al. [32] on smartphone strategies to influence physical activity, a total of 17 articles were reviewed. This study concluded that smartphone strategies tended to be ad hoc rather than theory-based [32].

In 2017, Stephenson et al. [15] systematically reviewed computer, mobile, and wearable technology SB interventions for healthy adults and found that these technologies can be effective in reducing SB. Their meta-analysis of 15 studies showed a mean reduction of $41 \mathrm{~min} /$ day in the intervention group at end-point follow-up. Another systematic review focusing solely on digital SB interventions was conducted by Huang et al. in 2019 [17]. This work differed from previous reviews by classifying technological features and annotated technological configurations of the interventions. In addition, they included engineering and computer science literature, while other reviews mainly included health and life science literature.

Including interventions from the field of engineering and computer science, but also the fields of industrial, architectural, and urban design research is of great importance when developing an understanding of the opportunities for future development of SB and PA interventions. It is in these fields especially that we see the development of new and explorative approaches and interventions using technology. By rapid prototyping, development, and piloting of novel digital technologies, these fields may lay the groundwork for the development of future health-promotion technologies.

In this paper, we reviewed recent interventions with a technological component aimed at reducing sedentary behavior or increasing physical activity of office workers. We included interventions from the fields of human computer interaction, engineering, computer sciences, and digital health. In our search, we not only included full text articles, but also case studies and work-in-progress papers. With this approach, we aimed to incorporate the latest ideas and developments in PA and SB interventions with a focus on the design of the interventions. Rather than focusing on the outcomes of the interventions, this review aimed to provide an overview of trends in how SB and PA interventions are shaped. By analyzing current approaches and trends in the form and function of the interventions, we identified 
underexplored possibilities and gaps for the design and development of future interventions and tools. We furthermore provide an increased understanding of the opportunities for future development of research and technologies that address sedentary behavior and physical activity in the office context.

The findings of this review can inform both the public health and design research fields, and address how the different fields can benefit from each other's work. An increased understanding between these research fields and multi-disciplinary expertise is crucial in the development and evaluation of digital health interventions [33]. This review therefore provides considerations for the development of future SB and PA interventions using technology, as well as implications for more collaborative and interdisciplinary work utilizing these interventions.

\section{Materials and Methods}

\subsection{Search and Selection}

A literature search was conducted in the Association for Computing Machinery (ACM) digital library, the interdisciplinary library Scopus, and the Institute of Electrical and Electronics Engineers (IEEE) Xplore Digital Library. The search included full-text scientific articles, case studies, and late-breaking work published between January 2009 and June 2019. All libraries were searched for designs or interventions aimed at increasing PA or reducing SB of knowledge workers using digital technology.

A search strategy was performed on title, abstract, and keywords using the following keywords: "sedentary" OR "sitting" OR "physical activity" OR "inactivity" AND "office OR work" AND "intervention" OR "design" OR "present" OR "propose". The search excluded "children" and "patient". To adjust the search to the nature of the different databases, two additions were made to the search queries. To limit the search in Scopus to designs with a digital component, the string "technology" OR "digital" was added. For the IEEE search, an extra exclusion string was added to exclude all SAT- and car-related papers. In addition to the database search, reference lists of existing reviews $[15,17,24]$ on workplace SB reduction and PA promotion were manually searched to identify additional eligible studies. Titles and abstracts were reviewed for eligibility based on the following including criteria:

1. Presents a design targeting reduction of SB or increasing PA or both;

2. Partly or exclusively during office hours;

3. Including digital technology in the delivery;

4. Published in peer-reviewed scientific journals or conference proceedings between 2009 and June 2019;

5. Published in the English language.

The selection of studies was done independently by the first two authors based on a screening of titles and abstracts. The selected papers were cross-checked, and any discrepancies were resolved by including a third author to reach a consensus about study inclusion.

\subsection{Data Synthesis}

A grounded approach was used to develop a coding scheme for analysis of the designs. Two authors independently coded nine designs for an initial coding scheme. Consensus on the scheme was sought by including a third and fourth author. Based on the coding scheme, all eligible studies were reviewed and the designs were annotated. The following information was extracted: publication data, design details like mode of delivery, underpinning theories, behavior change techniques, objectives, targeted behavior, and details on the input and output of the design. 


\section{Results}

\subsection{Study Selection}

A structured database search identified 1258 potentially relevant abstracts (Figure 1). After removing 128 duplicates, 1130 unique references remained. The titles and abstracts of these articles were screened, after which 61 articles were selected for potential inclusion (Figure 1). Out of those, papers were excluded if there was no design presented $(n=5)$, if it had no digital component $(n=2)$, if the intervention did not target SB or PA $(n=3)$, or if it did not partially or fully target the office environment $(n=6)$. In total, 45 relevant articles were included in this review (Table 1$)$.

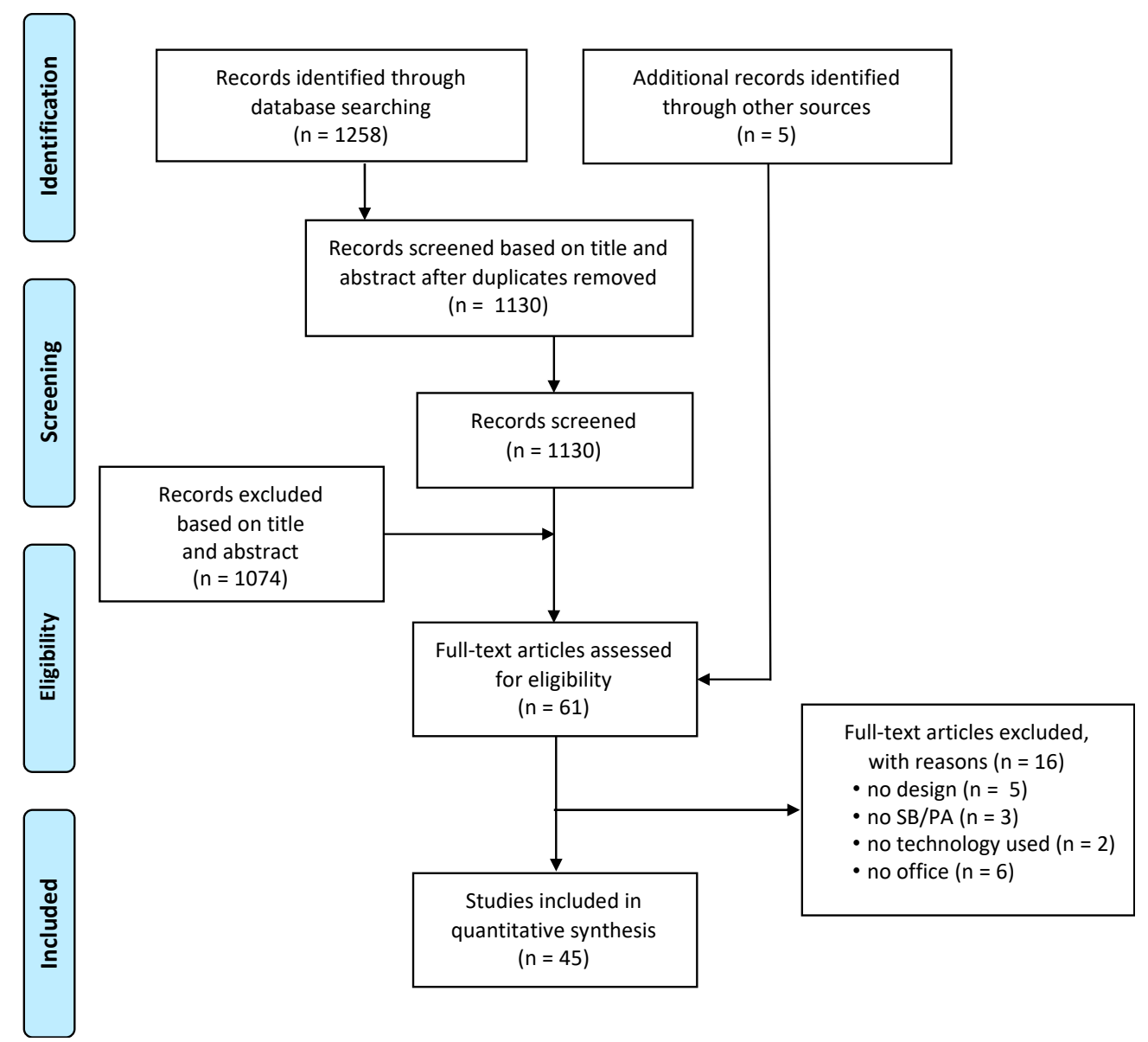

Figure 1. Selection of studies: PRISMA (Preferred Reporting Items for Systematic Reviews and Meta-Analyses) flowchart.

\subsection{Submission Type and Venue}

Of the 45 included papers (Figure 1), 9 were full text journal articles, 22 were full-text conference proceedings articles, and 14 were short (work-in-progress) conference papers. The 45 included papers presented 47 unique designs to combat physical inactivity. The studies were published in 27 different journals or conference proceedings between 2010 and 2019 (Figure 2) by 41 different first authors. Twenty-four studies were published in the field of human-computer interaction (HCI), 12 studies originated from computer science journals or conference proceedings, and 9 studies were published in the field of digital health. However, it must be noted that many of the journals and conferences had an interdisciplinary character; it was thus complex to make a clear demarcation of the research fields to precisely categorize the papers in this review. 
Table 1. Descriptions of included studies.

\begin{tabular}{|c|c|c|c|c|c|}
\hline & Study & Name of the Design & User Evaluation (n) & Description Design & Objective(s) of the Intervention \\
\hline 1 & Ahtinen et al. [34] & Brainwolk & 11 & $\begin{array}{l}\text { Walking meeting concept mediated with a } \\
\text { mobile app }\end{array}$ & $\begin{array}{c}\text { Encouraging and supporting the practice of } \\
\text { walking meetings }\end{array}$ \\
\hline 2 & Andersen et al. [35] & N.S. & 160 & Email-based encouragements & $\begin{array}{c}\text { Encouraging daily stair-walks together with } \\
\text { colleagues }\end{array}$ \\
\hline 3 & Arrogi et al. [36] & stAPP & 56 & Smartphone application & $\begin{array}{c}\text { Interrupting and reducing prolonged sitting } \\
\text { behavior }\end{array}$ \\
\hline 4 & Bonn et al. [37] & Health Integrator. & 209 & $\begin{array}{l}\text { Platform offering a variety of public, private, } \\
\text { and community services }\end{array}$ & $\begin{array}{l}\text { Healthier lifestyle behaviors (e.g., diet, } \\
\text { physical activity, sleep) }\end{array}$ \\
\hline 5 & Brandstetter \& Liebman [38] & Fidgebot & 4 & Nao robot & $\begin{array}{l}\text { Encouraging the use of standing desks and } \\
\text { "micro-exercises" }\end{array}$ \\
\hline 6 & Brombacher et al. [39] & Stimulight & 61 & $\begin{array}{l}\text { Tangible, ambient design to visualize } \\
\text { physical activity level and share it with } \\
\text { co-workers }\end{array}$ & $\begin{array}{c}\text { Improving physical activity level of office } \\
\text { workers }\end{array}$ \\
\hline 7 & Cambo et al. [40] & Breaksense & 6 & $\begin{array}{l}\text { Smartphone application using a Bluetooth } \\
\text { beacon infrastructure and a smartwatch }\end{array}$ & Encouraging mobility during breaks \\
\hline 8 & Damen et al. [41] & Workwalk & - & $\begin{array}{l}\text { Physical outdoor walking route, which could } \\
\text { be booked through the room booking system }\end{array}$ & $\begin{array}{l}\text { Encouraging and supporting the practice of } \\
\text { walking meetings }\end{array}$ \\
\hline 9 & Esakia et al. [42] & FitAware & 7 & $\begin{array}{l}\text { Three-component system including a } \\
\text { smartwatch interface, companion } \\
\text { application, and website. }\end{array}$ & $\begin{array}{l}\text { Encouraging group cohesion in physical } \\
\text { activity intervention }\end{array}$ \\
\hline 10 & Fortmann et al. [43] & MoveLamp & 10 & Ambient light display & $\begin{array}{l}\text { Moving more frequently and taking more } \\
\text { steps each day }\end{array}$ \\
\hline 11 & Foster et al. [44] & StepMatron & 10 & $\begin{array}{l}\text { Facebook application, designed to provide } \\
\text { social and competitive context for daily } \\
\text { pedometer }\end{array}$ & $\begin{array}{c}\text { Motivating physical activity in the working } \\
\text { environment }\end{array}$ \\
\hline 12 & Garcia et al. [45] & ESTHER 1.3 & 14 & Android pedometer application & $\begin{array}{l}\text { Active mini cycles of self-reflection on } \\
\text { physical activity }\end{array}$ \\
\hline 13 & Goldberg et al. [46] & Healthy Team Healthy U & 466 & Digital platform & $\begin{array}{l}\text { Team-based health promotion and wellness } \\
\text { program }\end{array}$ \\
\hline 14 & Gomes et al. [47] & Steptacular & 2980 & Online interactive incentive system & Encouraging people to walk more \\
\hline 15 & Grundgeiger et al. [48] & N.S. & 5 & Smartphone application & $\begin{array}{l}\text { Combating sedentary behavior based on } \\
\text { human movement research and distributed } \\
\text { prospective memory }\end{array}$ \\
\hline
\end{tabular}


Table 1. Cont

\begin{tabular}{|c|c|c|c|c|c|}
\hline & Study & Name of the Design & User Evaluation (n) & Description Design & Objective(s) of the Intervention \\
\hline 16 & Güldenpfennig et al. [49] & N.S. & 2 & $\begin{array}{l}\text { TV visualization including ambient light } \\
\text { system }\end{array}$ & $\begin{array}{l}\text { Establishing connectedness through the } \\
\text { shared experience of positive behavior } \\
\text { change }\end{array}$ \\
\hline 17 & Haque et al. [50] & iGo & 26 & Smartphone application & $\begin{array}{l}\text { Assisting employees in promoting their } \\
\text { physical activities }\end{array}$ \\
\hline 18 & Harjuniemi et al. [51] & Idle Stripes Shirt & - & Aesthetic, clothing-integrated display & $\begin{array}{l}\text { Creating awareness of immobility periods } \\
\text { during typical sitting-intensive office work }\end{array}$ \\
\hline 19 & He \& Agu [52] & On11 & 7 & Smartphone application & $\begin{array}{l}\text { Making people more aware of their } \\
\text { unhealthy behaviors by highlighting } \\
\text { sedentary behaviors }\end{array}$ \\
\hline 20 & Hirano et al. [53] & Walkminder & 8 & Smartphone application using vibrations & $\begin{array}{l}\text { Interrupting extended periods of inactivity } \\
\text { and encouraging a more active lifestyle }\end{array}$ \\
\hline 21 & Kanaoka \& Mutlu [54] & N.S. & 24 & $\begin{array}{l}\text { Humanlike NAO robot acting as a } \\
\text { motivational agent through motivational } \\
\text { interviewing }\end{array}$ & $\begin{array}{l}\text { Increasing motivation for behavior change } \\
\text { by talking about and reflecting on the causes } \\
\text { of lack of motivation }\end{array}$ \\
\hline 22 & Khot et al. (2013) [55] & Sweatatoms & - & $\begin{array}{l}\text { 3D-printed objects using the heartbeat } \\
\text { pattern }\end{array}$ & $\begin{array}{l}\text { Making the experience of participating in } \\
\text { physical activity more engaging beyond } \\
\text { screen-based feedback }\end{array}$ \\
\hline 23 & Khot et al. (2015) [56] & EdiPulse & - & $\begin{array}{l}\text { 3D-printed chocolates displaying cheerful } \\
\text { messages }\end{array}$ & $\begin{array}{l}\text { Opening new interaction possibilities } \\
\text { supporting the physical activity experience }\end{array}$ \\
\hline 24 & Khot et al. (2015) [57] & TastyBeats & NS & $\begin{array}{c}\text { A personalized sports drink representing the } \\
\text { user's heart rate data }\end{array}$ & $\begin{array}{l}\text { Expanding the understanding technology } \\
\text { potential to support the energy cycle when } \\
\text { being physically active }\end{array}$ \\
\hline 25 & Komninos et al. [58] & BeatClearWalker & 20 & $\begin{array}{l}\text { Smartphone application including a music } \\
\text { player }\end{array}$ & $\begin{array}{l}\text { Helping users to learn how to walk at a } \\
\text { moderate cadence }\end{array}$ \\
\hline 26 & Lin et al. [59] & Motivate & 6 & Smartphone application & $\begin{array}{l}\text { Providing personalized and contextualized } \\
\text { advice on physical activities }\end{array}$ \\
\hline 27 & Luo et al. [60] & Time for Break & 25 & A break-prompting system & $\begin{array}{l}\text { Enabling people to set their desired work } \\
\text { duration and prompting them to stand up or } \\
\text { move }\end{array}$ \\
\hline 28 & Madeira et al. [61] & Breakout & 10 & Ambient feedback prototype, tangible design & $\begin{array}{l}\text { Recommending breaks of sedentary } \\
\text { behavior at appropriate times }\end{array}$ \\
\hline 29 & Mateevitsi et al. [62] & Healthbar & 8 & Ambient persuasive device (light) & $\begin{array}{l}\text { Helping users break up their prolonged } \\
\text { sitting habits }\end{array}$ \\
\hline
\end{tabular}


Table 1. Cont

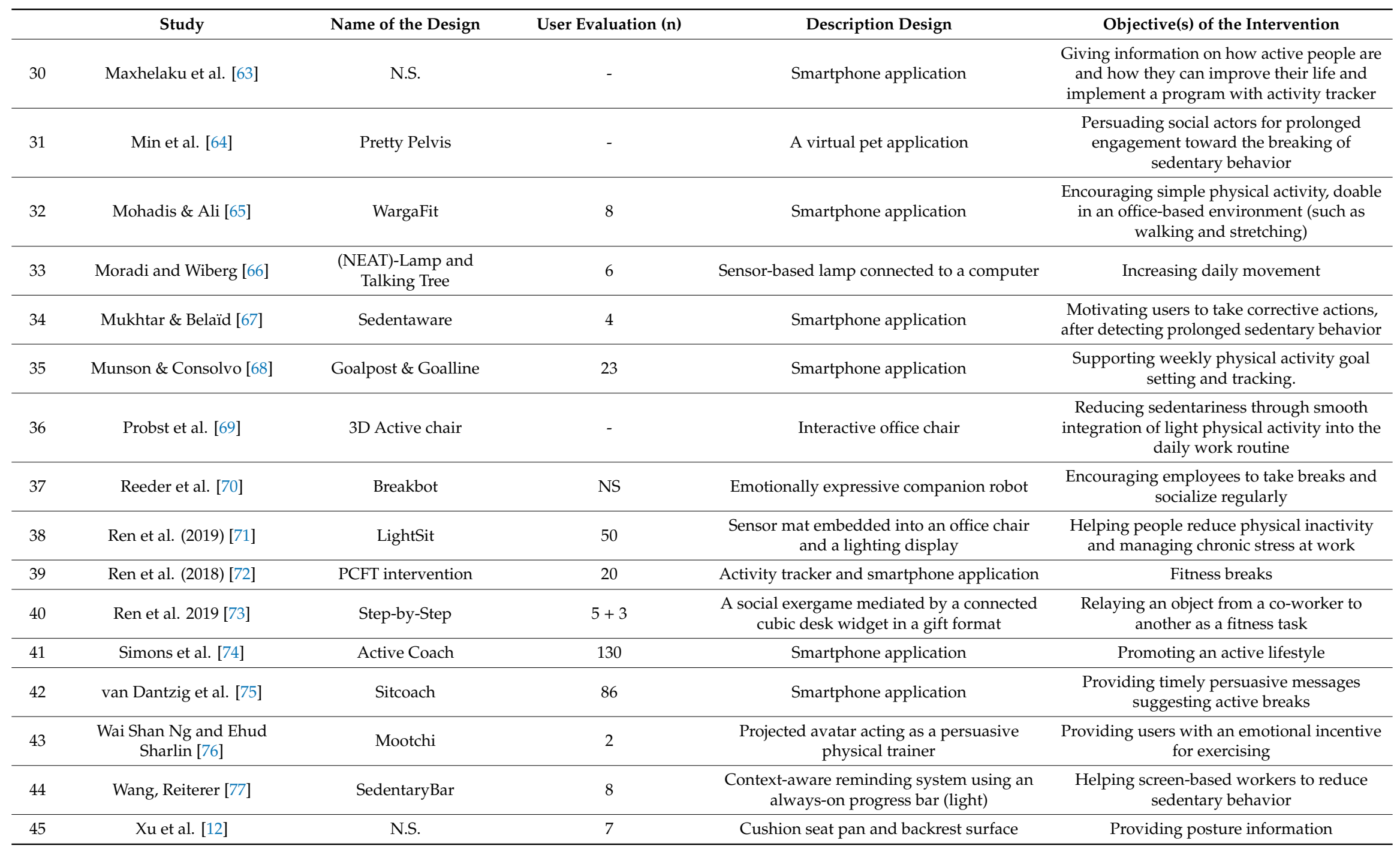




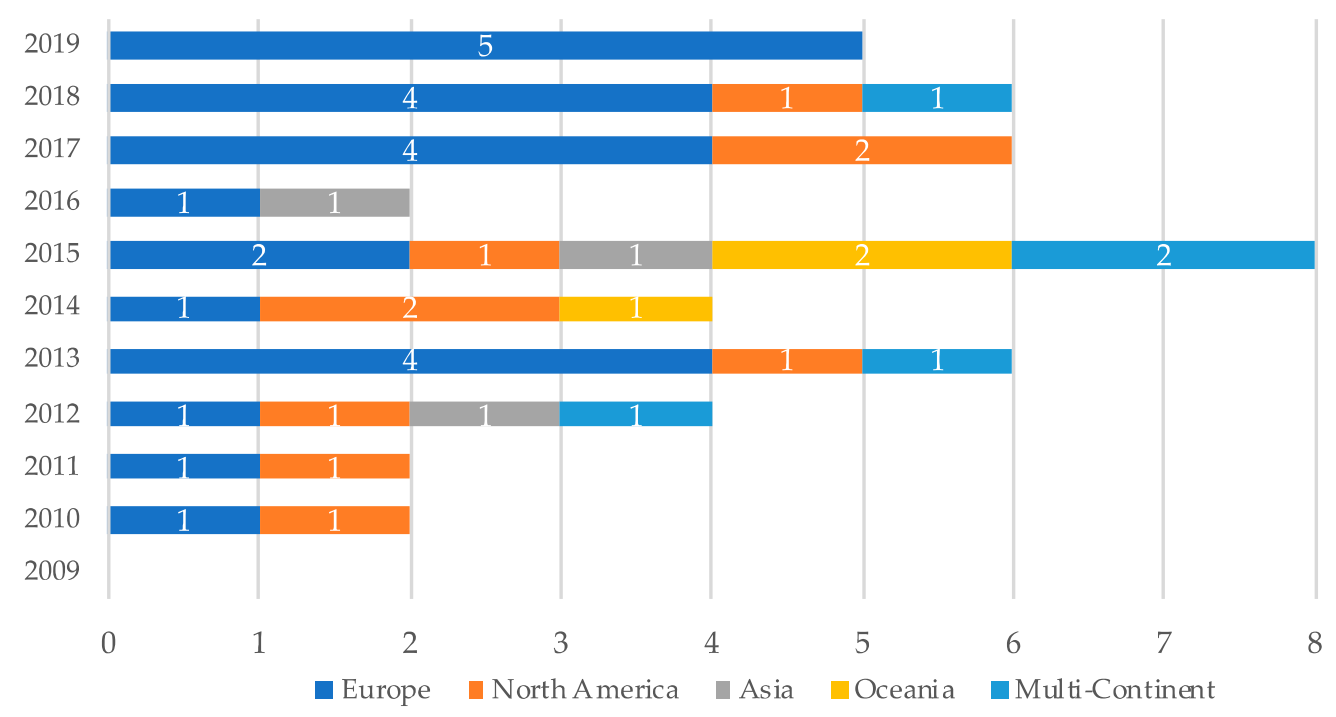

Figure 2. Number of included articles by year of publication and continent of authors.

\subsection{Theoretical Underpinning and Behavior Change Techniques}

Of the 45 studies, 34 did not specify a theoretical underpinning of their design. Of the 11 papers that did use a theoretical model, the most commonly used theory was the transtheoretical model $(25 \%)[37,58,68]$, followed by the theory of planned behavior $(17 \%)[41,46]$ and self-determination theory $(17 \%)[50,74]$. Five other papers based their designs on, respectively, persuasive system design model [65], goal setting theory [55], distributed prospective memory approach [48], social cognitive theory [38] and social learning theory combined with the theory of reasoned action [46].

Eighteen different behavior change techniques (BCT) were specified in the papers, although 17 studies did not specify any BCT (Table 2) The most commonly used BCT was the use of rewards, for instance through gamification processes (e.g., earning points). Another common strategy, included in nine papers, was to include social support or sharing experiences with peers in the intervention.

Table 2. Behavior change techniques used in the studies included in the analysis.

\begin{tabular}{cc}
\hline Behavior Change Technique & Studies \\
\hline Rewards & {$[36,40,42,44,47,49,50,55,57,63,68,70,78]$} \\
Creating awareness/self-reflection & {$[36,39,43,45,51,66,67]$} \\
Social support/sharing & {$[35,39,41,42,46,49,68,72,73]$} \\
Goal setting & {$[37,40,46,52,68,72,74]$} \\
Persuasion & {$[34,38,62,67,79]$} \\
Education/instruction/providing information & {$[12,35-37,74]$} \\
Prompting & {$[45,60,80]$} \\
Self-reflection/self-monitoring & {$[68,74]$} \\
Tailored feedback & {$[36,71]$} \\
Restructuring the physical environment & {$[34,41]$} \\
Restructuring the social environment & {$[41]$} \\
Reframing beliefs & {$[38,41]$} \\
Gamification & {$[40]$} \\
Motivational interviewing & {$[54]$} \\
Positive feedback & {$[76]$} \\
Habit formation & {$[41]$} \\
Social cues for motivation & {$[38]$} \\
Competition & {$[44]$} \\
Not specified & {$[48,53,58,59,61,65,69,75]$} \\
\hline
\end{tabular}




\subsection{Targeted Behavior}

Twenty-six interventions were specifically designed for the office environment, while 19 studies had a more generic approach in which they did not specify the context of use. Eight papers reported an evaluation of their intervention on SB or PA $[35,37,43,65,66,77,78]$. Thirty-three studies did not give a definition of PA or SB, while nine studies provided a definition of PA and four studies offered a definition of SB (Table 3).

Table 3. Studies defining sedentary behavior (SB) or physical activity (PA) in included interventions.

\begin{tabular}{cc}
\hline Targeted Behavior & Studies \\
\hline Physical activity & {$[35,43,46,53,58,65,66,74,77]$} \\
Sedentary behavior & {$[36,45,48,60]$} \\
Not defined & {$[12,34,37-42,44,47,49-52,54-57,59,61-64,67-73,75,76]$} \\
\hline
\end{tabular}

Although the majority of the papers did not provide a definition of SB or PA, a general distribution of the main targeted behavior could be made based on the description of the interventions. Just over half of the interventions targeted PA (24) while 9 interventions targeted SB and 12 targeted both PA and SB. More specifically, 18 interventions targeted break-taking behavior, 20 interventions targeted non-work-related PA, 3 interventions targeted work-related tasks, and 4 interventions were categorized as "other targeted behavior". The studies that were categorized as other targeted behavior included an intervention to moderate and maintain cadence [58], one intervention that stimulated connectedness using an ambient light system and PA visualizations on a screen [49], and two designs that targeted multiple lifestyle factors including diet, sleeping habits, and PA [37,46]. Of the three work-related behavior interventions, two designs aimed to stimulate walking meetings [41,49] and one intervention used movement on an interactive chair to control a workplace computer [69].

Another distinction could be made in the different approaches the interventions adopted to obtain the targeted behavior, namely creating awareness, creating opportunities, and teaching new behaviors (Table 4). The number of interventions that were classified as "creating awareness" exceeded the number of papers that stated intent to use awareness as a BCT, for instance because they used prompts to inform the user of prolonged sitting behavior. These interventions were categorized as creating awareness, even though this was not stated in the paper as a BCT. Twenty-three interventions aimed to create awareness of the user's current behavior to let them reflect and act on their behavior. The most commonly used form of delivery was via prompting or messages. This strategy was adopted by 18 interventions. Seven interventions aimed to create opportunities for users to perform the targeted behavior $[34,38,41,52,58,69,76]$. Only one intervention aimed to transform old behavior into new, healthier behavior. This study by Probst et al. [69] provided office workers with the possibility to use tilting, rotating, or bouncing movements on an interactive chair to control their workplace computer.

Table 4. Approaches in targeted behavior in the included interventions.

\begin{tabular}{cc}
\hline Approaches I Targeted Behavior & Studies \\
\hline Learning new behavior & {$[69]$} \\
Creating opportunities & {$[34,38,41,52,58,69,76]$} \\
Creating awareness & {$[12,35-37,39,40,42-51,53-57,59,60,62-68,70-77]$} \\
\hline
\end{tabular}

\subsection{Technology Type}

Several types of technology were used in the interventions (Table 5). Nineteen studies presented an intervention with a physical component (42\%), such as a robot or an interactive lamp, while 26 of the studies (57.8\%) showed purely digital designs like applications or computer software. Of the 19 studies with a physical component, 6 used a lamp as their primary feedback mechanism, 3 used a chair, 3 designs used robots, and 2 used 3D printing to represent physical activity (Figure 3; examples 
in Appendix A). Of the five remaining interventions with a physical component, one intervention used an ambient desk object [61], one intervention used an interactive fountain [57], one intervention integrated a physical line in a service design for walking meetings [41], and one was an interactive shirt [51].

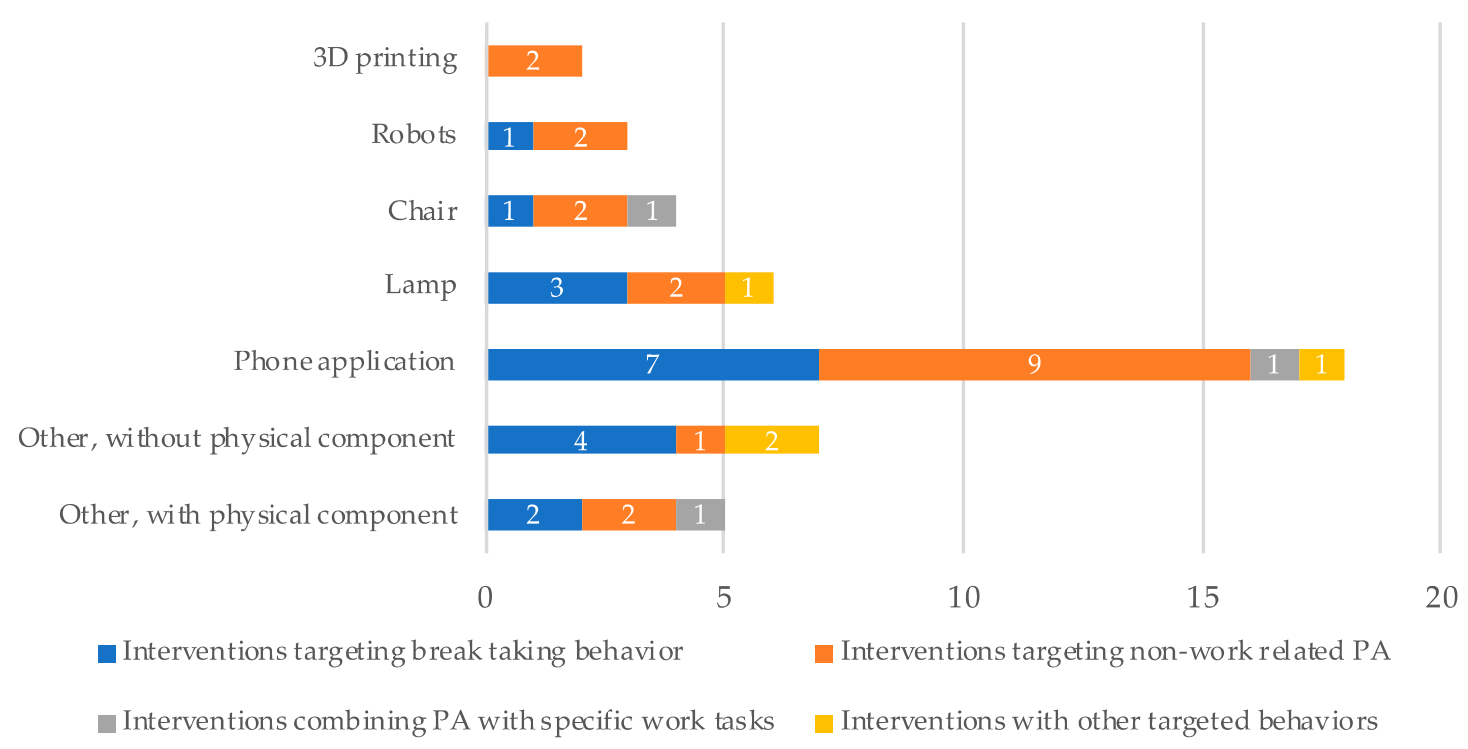

Figure 3. Approaches in targeted behavior in the included interventions with a physical component.

Twenty-four interventions were purely digital, of which phone applications were most common. Phone applications in combination with wearables were often used to give information or prompts, and as a data collection tool. Seven interventions did not have a physical component, of which one used break-prompting software [60], one used a projected avatar [76], one was an email-based intervention [35], and four were platform-based interventions [37,44,46,47]. Figure 3 shows the different types of technologies used by the interventions in relation to the targeted behavior.

Table 5. Technology types of included interventions.

\begin{tabular}{cc}
\hline Technology Type & Studies \\
\hline Lamp & {$[39,43,49,62,66,77]$} \\
Chair & {$[12,69,71,72]$} \\
Robots & {$[38,54,70]$} \\
3D printing & {$[55,56]$} \\
Phone application & {$[34,36,40,42,45,48,50,52,53,58,59,62,64,65,67,68,74,75]$} \\
Other, with physical component & {$[41,51,57,61,73]$} \\
Other, without physical component & {$[35,37,44,46,47,60,76]$} \\
\hline
\end{tabular}

Several types of objective data were collected as input measures by the interventions. Twenty-one interventions used step count as input, six measured heartrate, eight used motions or gestures as input, and three calculated caloric intake or energy expenditure (Table 6). Thirteen interventions used real-time data collection in their interventions.

Table 6. Input measures of included interventions.

\begin{tabular}{cc}
\hline Input Measures & Studies \\
\hline Step count & {$[1,4,5,13,16,29,31,32,37,41,46,48,52,54,57,62,68,71,72,74,81]$} \\
Heartrate & {$[38,40,55,57,71,78]$} \\
Motion or gestures & {$[48,52,61,62,66,69,76,77]$} \\
Caloric intake or energy expenditure & {$[37,52,63]$} \\
\hline
\end{tabular}


Of the 45 interventions, 7 employed existing infrastructures or tools. The tool most commonly used to build upon was the office chair $[12,69,71,72]$. Two interventions used office communication software in their design, by means of email [35] or a room booking system [41]. One intervention used a social communication channel (i.e., Facebook) as a platform for their design intervention [44].

In addition to the seven studies that used existing tools and digital services, there were two studies that restructured the built environment. The intervention "Breaksense" by Cambo et al. [40] introduced a Bluetooth beacon infrastructure to promote context-aware physical breaks within the workplace. Bluetooth beacons are low-energy devices that enable portable devices such as phones to be identified. By using this structure, Breaksense was able to trigger an action if a knowledge worker was close to a beacon, thereby encouraging workers to explore the office environment. Damen et al. [43] restructured the office campus environment by adding a physical line to their service design for walking meetings.

\section{Discussion}

This review set out to scope the landscape of technological sedentary behavior (SB) and physical activity (PA) interventions used in the office environment. Through a systematic literature search in the Association for Computing Machinery digital library, the interdisciplinary library Scopus, and the Institute of Electrical and Electronics Engineers Xplore Digital Library, we identified and analyzed 45 interventions published between 2009 and 2019. This paper provides an overview of the study characteristics, including a description of the interventions, intervention objectives, theoretical underpinning, and behavior change techniques. The analysis revealed two important gaps in the current research and development of technological SB and PA interventions.

A first underexplored opportunity in current interventions is the use of existing infrastructures. Seven studies employed existing office tools or systems, like chairs and emailing software. More often, interventions are offered as additional systems, tools, and services-an extra application on a phone or a robot is used to deliver SB or PA interventions. In future investigations, it might be possible to examine whether integrating interventions into existing office infrastructure will lower the threshold for people to use a system. Using existing systems and tools might limit additional the time investment required of users, which is an important design consideration for health-promotion interventions [11].

Second, the results showed that a clear distinction could be made in the objectives of the interventions. While a frequently adopted strategy of the interventions was supporting break-taking behavior, only a handful of studies attempted to create new, more active ways of working, i.e., how work can be transformed to be more physically active by making physical activity a more integral part of work and not merely a break from work, for instance by targeting walking meetings [41,79]. Only three studies targeted work-related tasks by transforming sedentary work behavior into physically active work behavior $[41,69,79]$. This finding was consistent despite the increased interest in sustainable performance at work, which extends the focus of worker health and wellbeing to health and wellbeing while maximizing work performance [82]. Interventions that focus on integrating physical activity with work may be more suitable to maximize work performance, compared to interventions that approach physical activity as a break from work. However, more work is needed on how SB and PA interventions can link to work performance.

In addition, the two most common intervention strategies in our review were rewarding "good" behavior and creating awareness of "bad" behavior. Other frequently used techniques included goal setting, persuasion, and creating social support. The use of these behavior change techniques is in line with previous work on effective strategies in SB interventions by Gardner et al. [83] and Bort et al. [32]. These reviews found that persuasion [83], goal setting, and social support [32] were among the most promising behavior change techniques for SB interventions. Other highlighted strategies were environmental restructuring (i.e., changing the physical or social context), education and training, self-monitoring, and problem solving $[32,83]$. However, these techniques were only seldom used in the interventions included in this review. Moreover, eight of the included studies did not specify any 
behavior change techniques. In future work, researchers should thus strive to formulate behavior change techniques more clearly to create a more unified terminology for intervention strategies.

In addition to formulating behavior change techniques, more clarity is needed on how SB and PA are defined within interventions. This review showed that a mere 12 of the included 45 interventions provided a definition of SB and PA. By adopting a unified terminology, a more profound exchange can be made between studies detailing development of interventions and evaluation studies. This can facilitate the adoption of novel technologies and interventions from design and engineering fields to be used in other fields. This is particularly important since the research and development of technological health interventions requires a multidisciplinary approach [33].

Our scoping review had a couple of limitations. First, by restricting our search to three databases, we may have excluded relevant publications. Similarly, by limiting our scope to scientific literature, we may have missed interventions that are used in practice but have not been reported on in the academic literature. We did, however, provide a broader scope than previous work by including short papers. By including exploratory or "late-breaking" work, we increased the chances of a more diverse scope of novel technologies being reviewed in this study. Focusing our review mainly on artefacts rather than studies, we obtained an overview of the strategies used and underused to address SB/PA in the context of office work. Although including short papers may have affected the level of information on interventions-and thus could have resulted in a lower overall quality of the included studies-this did not impede us in attaining the objectives of our study. Positioning this work as a scoping review of artefacts, we did not intend to report on the evaluation and impact of these technological interventions, and thus did not report on the methodological quality of the included studies or their reported results. Our present contribution instead focused on technology characteristics and identified current gaps and opportunities for future research and development of SB and PA interventions using technology.

\section{Conclusions}

In this investigation, we aimed to review the state-of-the-art technology interventions to reduce sedentary behavior or increase physical activity in the office environment, published in the fields of human computer interaction, engineering, computer science, and digital health and life sciences between 2009 and 2019. We included 45 interventions, identified using a systematic literature search. This study identified two main underexplored gaps and opportunities for future research and development of SB and PA interventions. With our work, we showed that current interventions make limited use of existing infrastructures and systems. The second major finding was that physical activity is approached as a break from work instead of an alternative, more active, way of working. Future work could investigate how physical activity can used as an active way of working instead of as a break from work. This new understanding should help to improve the understanding of current practice and provide opportunities for future research and development of SB and PA interventions. In addition, this work aimed to enhance the exchange of knowledge between different research fields and research phases by including papers reporting on the development of interventions as well as evaluation studies. We hope to improve a mutual understanding of the current SB and PA intervention practice, and thereby improve multidisciplinary work within the field of digital SB and PA interventions. Moreover, the list of artefacts can serve as an inspiration source for future development, and may help designers and developers to locate possibilities for novel design ideas [80].

Author Contributions: All authors together conceived the presented idea, under the lead of I.D., S.V., R.B., A.B., P.v.W., and C.L. supervised the project. I.D. designed the search model and analyzed the data. H.B., C.L. and S.V. aided in the analysis and in interpreting the results. H.B. contributed to the visuals and tables. I.D. wrote the original draft preparation. S.V., R.B., A.B., P.v.W., and C.L. reviewed, revised, and edited several earlier versions of this paper. All authors discussed the results and contributed to the final manuscript. All authors read and approved the final draft of the manuscript.

Funding: This research received no external funding.

Conflicts of Interest: The authors declare no conflict of interest. 


\section{Appendix A}
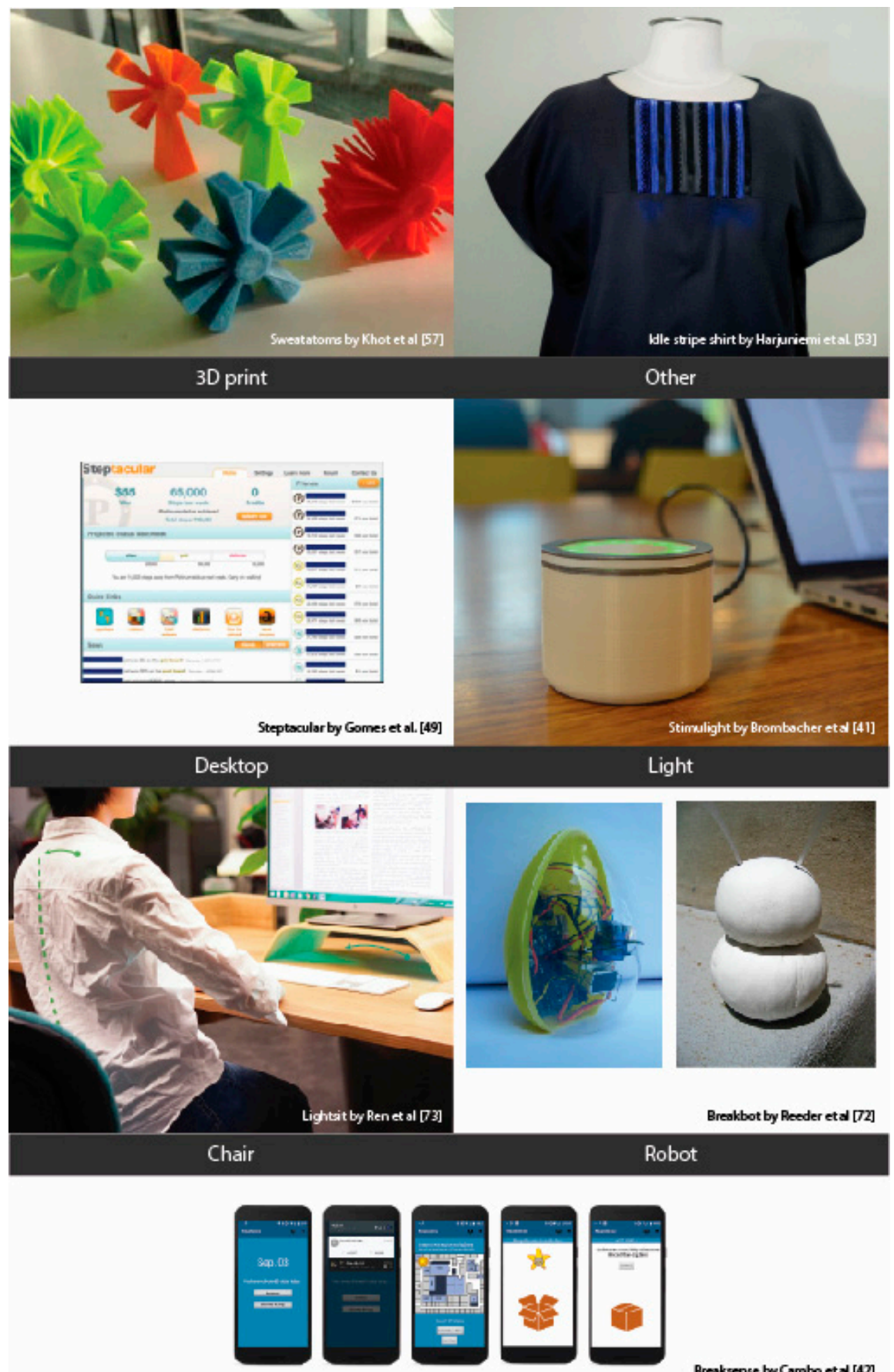

Breaksense byCombo et [4]

\section{Applications}

Figure A1. Examples of interventions categorized by technology types.

\section{References}

1. Guérin, E. Disentangling vitality, well-being, and quality of life: A conceptual examination emphasizing their similarities and differences with special application in the physical activity domain. J. Phys. Act. Health 2012, 9, 896-908. [CrossRef] [PubMed] 
2. Thivel, D.; Tremblay, A.; Genin, P.M.; Panahi, S.; Rivière, D.; Duclos, M. Physical Activity, Inactivity, and Sedentary Behaviors: Definitions and Implications in Occupational Health. Front. Public Heal. 2018, 6, 1-5. [CrossRef] [PubMed]

3. Healy, G.N.; Eakin, E.G.; LaMontagne, A.D.; Owen, N.; Winkler, E.A.H.; Wiesner, G.; Gunning, L.; Neuhaus, M.; Lawler, S.; Fjeldsoe, B.S.; et al. Reducing sitting time in office workers: Short-term efficacy of a multicomponent intervention. Prev. Med. (Baltim). 2013, 57, 43-48. [CrossRef] [PubMed]

4. Owen, N.; Sugiyama, T.; Eakin, E.E.; Gardiner, P.A.; Tremblay, M.S.; Sallis, J.F. Adults' sedentary behavior: Determinants and interventions. Am. J. Prev. Med. 2011, 41, 189-196. [CrossRef] [PubMed]

5. Schmid, D.; Ricci, C.; Leitzmann, M.F. Associations of objectively assessed physical activity and Sedentary time with all-cause mortality in US adults: The NHANES study. PLoS ONE 2015, 10, 3. [CrossRef] [PubMed]

6. Allender, S.; Peto, V.; Scarborough, P.; Kaur, A.; Rayner, M. Coronary heart disease statistics 2008 edition Contents. Br. Hear. Found. Heal. Promot. Res. Gr. 2008, 1-220.

7. Coombes, J.S.; Law, J.; Lancashire, B.; Fassett, R.G. "Exercise is medicine”: Curbing the burden of chronic disease and physical inactivity. Asia-Pac. J. Public Heal. 2015, 27, 600-605. [CrossRef]

8. Dempsey, P.C.; Owen, N.; Biddle, S.J.H.S.J.; Dunstan, D.W.D. Managing sedentary behavior to reduce the risk of diabetes and cardiovascular disease. Curr. Diab. Rep. 2014, 14, 1-26. [CrossRef]

9. Gibbs, B.B.; Hergenroeder, A.L.; Katzmarzyk, P.T.; Lee, I.; Jakicic, J.M. Definition, Measurement, and Health Risks Associated with Sedentary Behavior. Med. Sci. Sports Exerc. 2015, 47, 1295-1300. [CrossRef]

10. Martin, A.; Fitzsimons, C.; Jepson, R.; Saunders, D.H.; van der Ploeg, H.P.; Teixeira, P.J.; Gray, C.M.; Mutrie, N. Interventions with potential to reduce sedentary time in adults: Systematic review and meta-analysis. Br. J. Sports Med. 2015, 1-10. [CrossRef]

11. Patrick, K.; Hekler, E.B.; Estrin, D.; Mohr, D.C.; Riper, H.; Crane, D.; Godino, J.; Riley, W.T. The Pace of Technologic Change: Implications for Digital Health Behavior Intervention Research. Am. J. Prev. Med. 2016, 51, 816-824. [CrossRef]

12. Xu, L.; Chen, G.; Wang, J.; Shen, R.; Zhao, S. A sensing cushion using simple pressure distribution sensors. In Proceedings of the 2012 IEEE International Conference on Multisensor Fusion and Integration for Intelligent Systems (MFI), Hamburg, Germany, 13-15 September 2012; pp. 451-456.

13. Clemes, S.; O'connell, S.; Edwardson, C. Office workers' objectively measured sedentary behavior and physical activity during and outside working hours. J. Occup. Environ. Med. 2014, 56, 298-303. [CrossRef] [PubMed]

14. Kohl, H.W.; Craig, C.L.; Lambert, E.V.; Inoue, S.; Alkandari, J.R.; Leetongin, G.; Kahlmeier, S.; Andersen, L.B.; Bauman, A.E.; Blair, S.N.; et al. The pandemic of physical inactivity: Global action for public health. Lancet 2012, 380, 294-305. [CrossRef]

15. Stephenson, A.; McDonough, S.M.; Murphy, M.H.; Nugent, C.D.; Mair, J.L. Using computer, mobile and wearable technology enhanced interventions to reduce sedentary behaviour: A systematic review and meta-analysis. Int. J. Behav. Nutr. Phys. Act. 2017, 14, 105. [CrossRef] [PubMed]

16. Hazelzet, E.; Picco, E.; Houkes, I.; Bosma, H.; De Rijk, A. Effectiveness of interventions to promote sustainable employability: A systematic review. Int. J. Environ. Res. Public Health 2019, 16, 11. [CrossRef]

17. Huang, Y.; Benford, S.; Blake, H. Digital Interventions to Reduce Sedentary Behaviors of Office Workers: Scoping Review. J. Med. Internet Res. 2019, 21, e11079. [CrossRef]

18. Orji, R.; Moffatt, K. Persuasive technology for health and wellness: State-of-the-art and emerging trends. Health Inform. J. 2018, 24, 66-91. [CrossRef]

19. Stockwell, S.; Schofield, P.; Fisher, A.; Firth, J.; Jackson, S.E.; Stubbs, B.; Smith, L. Digital behavior change interventions to promote physical activity and/or reduce sedentary behavior in older adults: A systematic review and meta-analysis. Exp. Gerontol. 2019, 120, 68-87. [CrossRef]

20. Michie, S.; Yardley, L.; West, R.; Patrick, K.; Greaves, F. Developing and Evaluating Digital Interventions to Promote Behavior Change in Health and Health Care: Recommendations Resulting From an International Workshop. J. Med. Internet Res. 2017, 19, e232. [CrossRef]

21. Google Goals. Available online: https://www.blog.google/products/calendar/find-time-goals-googlecalendar/ (accessed on 28 September 2019).

22. Lee, M.K.; Kim, J.; Forlizzi, J.; Kiesler, S. Personalization revisited. In Proceedings of the 2015 ACM International Joint Conference on Pervasive and Ubiquitous Computing, Osaka, Japan, 9-11 September 2015; pp. 743-754. 
23. Chau, J.Y.; Van Der Ploeg, H.P.; van Uffelen, J.G.Z.; Wong, J.; Riphagen, I.; Healy, G.N.; Gilson, N.D.; Dunstan, D.W.; Bauman, A.E.; Owen, N.; et al. Are workplace interventions to reduce sitting effective? A systematic review. Prev. Med. (Baltim). 2010, 51, 352-356. [CrossRef]

24. Gilson, N.D.; Puig-Ribera, A.; McKenna, J.; Brown, W.J.; Burton, N.W.; Cooke, C.B. Do walking strategies to increase physical activity reduce reported sitting in workplaces: A randomized control trial. Int. J. Behav. Nutr. Phys. Act. 2009, 6, 1-7. [CrossRef] [PubMed]

25. Marshall, A.L.; Leslie, E.R.; Bauman, A.E.; Marcus, B.H.; Owen, N. Print versus website physical activity programs: A randomized trial. Am. J. Prev. Med. 2003, 25, 88-94. [CrossRef]

26. Plotnikoff, R.C.; McCargar, L.J.; Wilson, P.M.; Loucaides, C.A. Efficacy of an e-mail intervention for the promotion of physical activity and nutrition behavior in the workplace context. Am. J. Heal. Promot. 2005, 19, 422-429. [CrossRef] [PubMed]

27. Shrestha, N.; Ijaz, S.; Kukkonen-Harjula, K.T.; Kumar, S.; Nwankwo, C.P. Workplace interventions for reducing sitting at work. Cochrane Database Syst. Rev. 2014, 2014, 1.

28. Evans, R.E.; Fawole, H.O.; Sheriff, S.A.; Dall, P.M.; Grant, P.M.; Ryan, C.G. Point-of-choice prompts to reduce sitting time at work: A randomized trial. Am. J. Prev. Med. 2012, 43, 293-297. [CrossRef]

29. Pedersen, S.J.; Cooley, P.D.; Mainsbridge, C. An e-health intervention designed to increase workday energy expenditure by reducing prolonged occupational sitting habits. Work 2014, 49, 289-295. [CrossRef]

30. Swartz, A.M.; Rote, A.E.; Welch, W.A.; Maeda, H.; Hart, T.L.; Cho, Y.I.; Strath, S.J. Prompts to Disrupt Sitting Time and Increase Physical Activity at Work, 2011-2012. Prev. Chronic Dis. 2014, 11, 1-8. [CrossRef]

31. Gordon, A. A Theory-Based Pilot Study to Decrease Sitting Time in the Workplace. Master's Thesis, Arizona State University, Tempe, Arizona, 2013.

32. Bort-Roig, J.; Gilson, N.D.; Puig-Ribera, A.; Contreras, R.S.; Trost, S.G. Measuring and influencing physical activity with smartphone technology: A systematic review. Sport. Med. 2014, 44, 671-686. [CrossRef]

33. Blandford, A.; Gibbs, J.; Newhouse, N.; Perski, O.; Singh, A.; Murray, E. Seven lessons for interdisciplinary research on interactive digital health interventions. Digit. Heal. 2018, 4, 1-14. [CrossRef]

34. Ahtinen, A.; Andrejeff, E.; Väänänen, K.; Vaananen, K. Brainwolk: A Mobile Technology Mediated Walking Meeting Concept for Wellbeing and Creativity at Work. In Proceedings of the 15th International Conference on Mobile and Ubiquitous Multimedia, Rovaniemi, Finland, 13-15 December 2016; ACM: New York, NY, USA, 2016; pp. 307-309.

35. Andersen, L.L.; Sundstrup, E.; Boysen, M.; Due Jakobsen, M.; Mortensen, O.S.; Persson, R. Cardiovascular health effects of internet-based encouragements to do daily workplace stair-walks: Randomized controlled trial. J. Med. Internet Res. 2013, 15, 6. [CrossRef]

36. Arrogi, A.; Bogaerts, A.; Seghers, J.; Devloo, K.; Vanden Abeele, V.; Geurts, L.; Wauters, J.; Boen, F. Evaluation of stAPP: A smartphone-based intervention to reduce prolonged sitting among Belgian adults. Health Promot. Int. 2017, 34, 16-27. [CrossRef] [PubMed]

37. Bonn, S.E.; Lof, M.; Ostenson, C.-G.; Trolle Lagerros, Y. App-technology to improve lifestyle behaviors among working adults—-the Health Integrator study, a randomized controlled trial. BMC Public Health 2019, 19, 273.

38. Brandstetter, J.; Liebman, N.; London, K. Fidgebot: Working Out While Working. In Proceedings of the Tenth Annual ACM/IEEE International Conference on Human-Robot Interaction Extended Abstracts, Portland, OR, USA, 2-5 March 2015; ACM: New York, NY, USA, 2015; pp. 149-150.

39. Brombacher, H.; Megens, C.; Vos, S.; Arts, D.; Megens, C.; Vos, S. Stimulight: Exploring Social Interaction to Reduce Physical Inactivity among Office Workers. In Proceedings of the 37th ACM International Conference on Human Factors in Computing Systems (CHI2019), Glasgow, UK, 4-9 May 2019; pp. 1-6.

40. Cambo, S.A.; Avrahami, D.; Lee, M.L. BreakSense: Combining Physiological and Location Sensing to Promote Mobility During Work-Breaks. In Proceedings of the 2017 CHI Conference on Human Factors in Computing Systems, Denver, CO, USA, 6 May 2017; ACM: New York, NY, USA, 2017; pp. 3595-3607.

41. Damen, I.; Brankaert, R.; Megens, C.; van Wesemael, P.; Brombacher, A.; Vos, S. Let's Walk and Talk: A Design Case to Integrate an Active Lifestyle in Daily Office Life. In Proceedings of the Extended Abstracts of the 2018 CHI Conference on Human Factors in Computing Systems, Montreal, QC, Canada, 21 April 2018; ACM: New York, NY, USA, 2018; pp. 10:1-10:10. 
42. Esakia, A.; Harden, S.M.; McCrickard, D.S.; Horning, M. FitAware: Channeling Group Dynamics Strategies with Smartwatches in a Physical Activity Intervention. In Proceedings of the $2017 \mathrm{CHI}$ Conference Extended Abstracts on Human Factors in Computing Systems, Denver, CO, USA, 6-11 May 2017; ACM: New York, NY, USA, 2017; pp. 2551-2559.

43. Fortmann, J.; Stratmann, T.C.; Boll, S.; Poppinga, B.; Heuten, W. Make Me Move at Work! An Ambient Light Display to Increase Physical Activity. In Proceedings of the 7th International Conference on Pervasive Computing Technologies for Healthcare, Venice, Italy, 5-8 May 2013; pp. 274-277.

44. Foster, D.; Linehan, C.; Kirman, B.; Lawson, S.; James, G.; Heath, B. Motivating physical activity at work: Using persuasive social media for competitive step counting. In Proceedings of the 14th International Academic MindTrek Conference: Envisioning Future Media Environments, Tampere, Finland, 6 October 2010; pp. 111-116.

45. Garcia, J.J.; Romero, N.A.; Keyson, D.; Havinga, P. Esther 1.3: Integrating in-situ prompts to trigger self-reflection of physical activity in knowledge workers. In Proceedings of the ChileCHI '13, Temuco, Chile, 11-15 November 2013; pp. 1-4.

46. Goldberg, L.; Lockwood, C.; Garg, B.; Kuehl, K.S. Healthy Team Healthy U: A Prospective Validation of an Evidence-Based Worksite Health Promotion and Wellness Platform. Front. Public Heal. 2015, 3, 1-12. [CrossRef] [PubMed]

47. Gomes, N.; Merugu, D.; O’Brien, G.; Mandayam, C.; Yue, J.S.; Atikoglu, B.; Albert, A.; Fukumoto, N.; Liu, H.; Prabhakar, B.; et al. Steptacular: An incentive mechanism for promoting wellness. In Proceedings of the Fourth International Conference on Communication Systems and Networks (COMSNETS 2012), Bangalore, India, 3-7 January 2012; pp. 1-6.

48. Grundgeiger, T.; Pichen, J.; Häfner, J.; Wallmann-Sperlich, B.; Löffler, D.; Huber, S. Combating Sedentary Behavior: An App Based on a Distributed Prospective Memory Approach. In Proceedings of the 2017 CHI Conference Extended Abstracts on Human Factors in Computing Systems, Denver, CO, USA, 6 May 2017; pp. 1632-1639.

49. Güldenpfennig, F.; Ganhör, R.; Fitzpatrick, G. Sitting in the Same Boat: A Case Study of a Combined Awareness System and Behaviour Change Technology. In Proceedings of the Annual Meeting of the Australian Special Interest Group for Computer Human Interaction, Parkville, Australia, 7 December 2015; ACM: New York, NY, USA, 2015; pp. 309-313.

50. Haque, M.S.; Abdullah, W.M.; Rahaman, S.; Kangas, M.; Jämsä, T. Persuasive health and wellbeing application: A theory-driven design in promoting physical activity. In Proceedings of the 2016 International Conference on Medical Engineering, Health Informatics and Technology (MediTec), Dhaka, Bangladesh, 17-18 December 2016; pp. 1-5.

51. Harjuniemi, E.; Colley, A.; Rytilahti, P.; Li, H.; Forest, J.; Häkkilä, J. Idle Stripes Shirt: Ambient Wearable Display for Activity Tracking. In Proceedings of the 2018 ACM International Symposium on Wearable Computers, Singapore, 8-12 October 2018; ACM: New York, NY, USA, 2018; pp. 254-259.

52. He, Q.; Agu, E. On11: An Activity Recommendation Application to Mitigate Sedentary Lifestyle. In Proceedings of the 2014 workshop on physical analytics, Bretton Woods, NH, USA, 16 June 2014; pp. 3-8.

53. Hirano, S.H.; Farrell, R.G.; Danis, C.M.; Kellogg, W.A. WalkMinder: Encouraging an Active Lifestyle Using Mobile Phone Interruptions. In Proceedings of the CHI '13 Extended Abstracts on Human Factors in Computing Systems, Paris France, 27 April-2 May 2013; ACM: New York, NY, USA, 2013; pp. 1431-1436.

54. Kanaoka, T.; Mutlu, B. Designing a Motivational Agent for Behavior Change in Physical Activity. In Proceedings of the CHI '15, Seoul, Korea, 18-23 April 2015; pp. 1445-1450.

55. Khot, R.A.; Mueller, F.; Hjorth, L. SweatAtoms: Materializing Physical Activity. In Proceedings of the 9th Australasian Conference on Interactive Entertainment: Matters of Life and Death, Melbourne, Australia, 30 September 2013; ACM: New York, NY, USA, 2013; pp. 4:1-4:7.

56. Khot, R.A.; Lee, J.; Hjorth, L.; Mueller, F. “Floyd” SweatAtoms: Understanding Physical Activity Through Material Artifacts. In Proceedings of the CHI '14 Extended Abstracts on Human Factors in Computing Systems, Toronto, ON, Canada, 26 April-1 May 2014; ACM: New York, NY, USA, 2014; pp. 173-174.

57. Khot, R.A.; Lee, J.; Hjorth, L.; Mueller, F. “Floyd” TastyBeats: Celebrating Heart Rate Data with a Drinkable Spectacle. In Proceedings of the Ninth International Conference on Tangible, Embedded, and Embodied Interaction, Stanford, CA, USA, 15 January 2015; ACM: New York, NY, USA, 2015; pp. 229-232. 
58. Komninos, A.; Dunlop, M.; Rowe, D.; Hewitt, A.; Coull, S. Using Degraded Music Quality to Encourage a Health Improving Walking Pace: BeatClearWalker. In Proceedings of the 2015 9th International Conference on Pervasive Computing Technologies for Healthcare (PervasiveHealth), Istanbul, Turkey, 20-23 May 2015.

59. Lin, Y.; Jessurun, J.; de Vries, B.; Timmermans, H. Motivate: Towards Context-Aware Recommendation Mobile System for Healthy Living. In Proceedings of the 2011 5th International Conference on Pervasive Computing Technologies for Healthcare (PervasiveHealth) and Workshops, Dublin, Ireland, 23-26 May 2011; pp. 250-253.

60. Luo, Y.; Lee, B.; Yvette Wohn, D.; Rebar, A.L.; Conroy, D.E.; Kyoung Choe, E. Time for Break: Understanding Information Workers' Sedentary Behavior Through a Break Prompting System. In Proceedings of the 2018 ACM Conference on Human Factors in Computing Systems (CHI), Montreal, QC, Canada, 21-26 April 2018; pp. 1-14.

61. Ferreira, M.J.; Caraban, A.K.; Karapanos, E. Breakout: Predicting and breaking sedentary behaviour at work. In Proceedings of the Conference on Human Factors in Computing Systems, Toronto, ON, Canada, 26-30 April 2014; pp. 2407-2412.

62. Mateevitsi, V.; Reda, K.; Leigh, J.; Johnson, A. The Health Bar: A Persuasive Ambient Display to improve the office worker's well being. In Proceedings of the 5th Augmented Human International Conference, Kobe, Japan, 7-9 March 2014; p. 21.

63. Maxhelaku, S.; Veliu, A.; Kika, A.; Greca, S. The use of a smart application to track activities for achieving an active and healthy life recently characterizing the world. In Proceedings of the RTA-CSIT, Tirana, Albania, 23-24 November 2018.

64. Min, D.A.; Kim, Y.; Jang, S.A.; Kim, K.Y.; Jung, S.-E.; Lee, J.-H. Pretty Pelvis. In Proceedings of the 33rd Annual ACM Conference Extended Abstracts on Human Factors in Computing Systems, Seoul, Korea, 18-23 April 2015; pp. 1259-1264.

65. Mohadis, H.M.; Ali, N.M. Designing persuasive application to encourage physical activity at workplace among older workers. In Proceedings of the 2016 Sixth International Conference on Digital Information and Communication Technology and its Applications (DICTAP), Konya, Turkey, 21-23 July 2016; pp. 126-130.

66. Moradi, F.; Wiberg, M. NEAT-Lamp and Talking Tree: Beyond Personal Informatics towards Active Workplaces. Computers 2017, 7, 4. [CrossRef]

67. Mukhtar, H.; Belaid, D. Using adaptive feedback for promoting awareness about physical activeness in adults. In Proceedings of the 2013 IEEE 10th International Conference on Ubiquitous Intelligence and Computing and 2013 IEEE 10th International Conference on Autonomic and Trusted Computing, Vietri sul Mere, Italy, 18-21 December 2013; pp. 638-643.

68. Munson, S.; Consolvo, S. Exploring Goal-setting, Rewards, Self-monitoring, and Sharing to Motivate Physical Activity. In Proceedings of the 6th International Conference on Pervasive Computing Technologies for Healthcare, San Diego, CA, USA, 21-24 May 2012; pp. 25-32.

69. Probst, K.; Lindlbauer, D.; Greindl, P.; Trapp, M.; Haller, M.; Schwartz, B.; Schrempf, A. Rotating, Tilting, Bouncing: Using an Interactive Chair to Promote Activity in Office Environments. In Proceedings of the CHI '13 Extended Abstracts on Human Factors in Computing Systems, Paris, France, 27 April-2 May 2013; ACM: New York, NY, USA, 2013; pp. 79-84.

70. Reeder, S.; Kelly, L.; Kechavarzi, B.; Sabanovic, S. Breakbot: A Social Motivator for the Workplace. In Proceedings of the 8th ACM Conference on Recommender systems, Foster City, CA, USA, 6-10 October 2014; pp. 61-64.

71. Ren, X.; Yu, B.; Lu, Y.; Zhang, B.; Hu, J.; Brombacher, A. LightSit: An unobtrusive health-promoting system for relaxation and fitness microbreaks at work. Sensors (Switzerland) 2019, 19, 2162. [CrossRef]

72. Ren, X.; Yu, B.; Lu, Y.; Brombacher, A. Exploring Cooperative Fitness Tracking to Encourage Physical Activity Among Office Workers. Proc. ACM Hum.-Comput. Interact. 2018, 2, 146:1-146:20. [CrossRef]

73. Ren, X.; Hollander, L.; Van Der Marel, R.; Molenaar, L.; Lu, Y. Step-by-step: Exploring a social exergame to encourage physical activity and social dynamics among office workers. Conf. Hum. Factors Comput. Syst. Proc. 2019, 1-6.

74. Simons, D.; De Bourdeaudhuij, I.; Clarys, P.; De Cocker, K.; Vandelanotte, C.; Deforche, B. Effect and process evaluation of a smartphone app to promote an active lifestyle in lower educated working young adults: Cluster randomized controlled trial. JMIR mHealth uHealth 2018, 6, 8. [CrossRef] 
75. Van Dantzig, S.; Geleijnse, G.; Van Halteren, A.T. Toward a persuasive mobile application to reduce sedentary behavior. Pers. Ubiquitous Comput. 2013, 17, 1237-1246. [CrossRef]

76. Shan, W.; Ng, F.; Sharlin, E. Exercise Pal Mootchi. In Proceedings of the International Conference on Entertainment Computing ICEC 2011, Vancouver, BC, Canada, 5-8 October 2011; pp. 395-398.

77. Wang, Y.; Reiterer, H. The Point-of-Choice Prompt or the Always-On Progress Bar? In Proceedings of the CHI'19 Extended Abstracts, Glasgow, Scotland, UK, 4-9 May 2019; pp. 1-6.

78. Khot, R.A.; Pennings, R.; Mueller, F. "Floyd” EdiPulse: Turning Physical Activity Into Chocolates. In Proceedings of the 33rd Annual ACM Conference Extended Abstracts on Human Factors in Computing Systems, Seoul, Korea, 18-23 April; ACM: New York, NY, USA, 2015; pp. 331-334.

79. Ahtinen, A.; Andrejeff, E.; Harris, C.; Väänänen, K. Let's Walk at Work-Persuasion through the Brainwolk Walking Meeting App Full Paper Towards Physically Active Ways of Work. AcademicMindtrek 2017, 2017, 73-82.

80. Yoo, S.; Xue, L.; Kay, J. HappyFit. In Proceedings of the Adjunct Publication of the 25th Conference on User Modeling, Adaptation and Personalization, Bratislava, Slovakia, 9 July 2017; pp. 391-394.

81. Hassenzahl, M.; Heidecker, S.; Eckoldt, K.; Diefenbach, S.; Hillmann, U. All you need is love: Current strategies of mediating intimate relationships through technology. ACM Trans. Comput. Interact 2012, 19, 30:1-30:19. [CrossRef]

82. De Jonge, J.; Peeters, M.C.W. The vital worker: Towards sustainable performance at work. Int. J. Environ. Res. Public Health 2019, 16, 910. [CrossRef] [PubMed]

83. Gardner, B.; Smith, L.; Lorencatto, F.; Hamer, M.; Biddle, S.J.H. How to reduce sitting time? A review of behaviour change strategies used in sedentary behaviour reduction interventions among adults. Health Psychol. Rev. 2016, 10, 89-112. [CrossRef] [PubMed]

(C) 2020 by the authors. Licensee MDPI, Basel, Switzerland. This article is an open access article distributed under the terms and conditions of the Creative Commons Attribution (CC BY) license (http://creativecommons.org/licenses/by/4.0/). 